\title{
Relationship between sexual abstinence of men and chromosomally abnormal spermatozoa*
}

\author{
F. Pellestor and B. Sèle \\ Cytogenetic and Reproductive Biology Laboratory, Grenoble University Medical School, \\ F-38700 Grenoble, France
}

\begin{abstract}
Summary. Epidemiological and mouse cytogenetic studies have suggested the existence of a positive relationship between the frequency of chromosomal abnormalities and the duration of male sexual abstinence. A cytogenetic analysis of human spermatozoa was performed with 4 men after periods of sexual abstinence ranging from 2 to 15 days. Using hamster eggs for penetration, 934 sperm chromosome complements were obtained. The overall frequency of sperm chromosomal abnormalities was $9 \cdot 4 \%$. There was no correlation between the length of sexual abstinence and each type of chromosomal abnormality. Our results do not support the hypothesis of an increased risk of aberration with duration of abstinence.
\end{abstract}

Keywords: sexual abstinence; man; sperm chromosomes; hamster egg penetration assay; ageing

\section{Introduction}

The ageing of gametes has a detrimental effect on both fertilization and early embryonic development. Rapid deterioration of the eggs after ovulation is believed to account for many of the observed abnormalities. Nogués et al. (1988) have found a correlation between oocyte ageing and a change in the structure of the zona pellucida which could affect the fertilization procedure. Donahue \& Karp (1973) reported an increase in parthenogenesis and haploid/diploid mosaicism in old fertilizable mouse oocytes. Mouse oocytes aged in vitro also show an increase in the incidence of chromosomal abnormalities (Santalo et al., 1986). In man, an increase in the frequency of spontaneous abortions has been linked to postovulatory ageing of eggs (Boué et al., 1975). The role of paternal ageing in the occurrence of chromosomal abnormalities is less known but an increased frequency of trisomy 21 with advanced paternal age has been reported (Stene et al., 1977). Independent of the mother's age, the occurrence of Down's syndrome has been associated with a decreased coital frequency (Milstein-Moscati \& Becak, 1981). These data suggest that long intervals of abstinence could result in an increase of fertilization abnormalities.

Martin-Deléon \& Boice $(1982,1985)$ have studied the incidence of chromosomal abnormalities in mouse zygotes resulting from sperm ageing in the vas both experimentally and after sexual abstinence; there was a significant increase of all chromosomal abnormalities with the male genome being implicated more often that the female one in their origin. It was suggested that ageing of spermatozoa could alter the condition of competition between chromosomally balanced and unbalanced spermatozoa in such a way that chromosomally abnormal spermatozoa could gain an advantage either in number or in fertilizing ability.

In man, it is well known that the length of abstinence influences some of the semen characteristics (Poland et al., 1985), but until now, no chromosomal investigations have been performed. Human sperm chromosomes can be analysed after fusion with golden hamster eggs (Martin et al.,

\footnotetext{
${ }^{*}$ Reprint requests to Dr Bernard Sèle.
} 
1987; Pellestor \& Sèle, 1989). The present study was performed to determine whether sexual abstinence exerts a similar effect in man.

\section{Materials and Methods}

This study was carried out on volunteers. Criteria for their inclusion were that: (1) they were healthy and not currently undergoing treatment for any illness and that they had never been exposed to a known mutagen; (2) their lymphocyte karyotype was normal; (3) they had a normal spermogram (sperm concentration $\geq 4 \times 10^{7} / \mathrm{ml}$; progressive motility $>50 \%$ ); and (4) they agreed to abstain from intercourse for periods of $2,4,7,10$ and 15 days. The order of these abstinence periods was chosen by themselves.

Although 7 men conformed to the biological criteria, after being informed about the anticipated sexual abstinences, only 4 were willing to participate in this study. All of them were non-smokers and their ages ranged from 22 to 30 years. Semen was collected by masturbation at the laboratory. Semen analysis was performed on each specimen. The techniques for preparation of human spermatozoa and hamster eggs, culture of penetrated eggs and chromosome preparation have been previously described (Sèle et al., 1985). The chromosomes were R-banded. To assess the intra-individual variation in the incidence of sperm chromosomal abnormalities, two experiments, each with a 2 days' abstinence, were performed within a 4-month interval. The correlation between the length of abstinence and the total frequency of sperm chromosomal abnormalities was tested by $\chi^{2}$ analysis. The proportions of both numerical and structural abnormalities in relation to the abstinence periods were also compared by $\chi^{2}$ analysis. Regression analysis was used to analyse the relationship between length of abstinence and each of the frequencies of numerical abnormalities and structural abnormalities.

\section{Results}

Three of the 4 volunteers were able to comply with the 5 abstinence periods. The fourth failed to respect both the 10- and 15-day delays and only one 12-day abstinence semen sample was collected. In all, 23 ejaculates were collected; the penetration rate of hamster eggs was always greater than $50 \%$, with a $1-3 \mathrm{~h}$ gamete co-incubation.

Altogether, 934 sperm chromosome complements were obtained (Fig. 1): the mean number of karyotypes per sample was 36 , with a range of 30-75 (Table 1). The results of this study are presented in detail in Table 2. The mean frequency of chromosomal abnormalities was $9 \cdot 4 \%$ $(6 \cdot 9-13 \cdot 2 \%$ ). The most frequent type of abnormality was hypohaploidy (from $2 \cdot 9$ to $7 \cdot 1 \%$ ).

Table 1. Summary of types of abnormalities of 934 sperm chromosome complements

\begin{tabular}{lccccc}
\hline Donor & $\begin{array}{c}\text { Age } \\
\text { (years) }\end{array}$ & $\begin{array}{c}\text { No. of } \\
\text { karyotypes }\end{array}$ & $\begin{array}{c}\text { Mean \% } \\
\text { numerical } \\
\text { abnormalities }\end{array}$ & $\begin{array}{c}\text { Mean \% } \\
\text { structural } \\
\text { abnormalities }\end{array}$ & $\begin{array}{c}\text { Mean \% } \\
\text { total } \\
\text { abnormalities }\end{array}$ \\
\hline A & 25 & 279 & $8 \cdot 9$ & $3 \cdot 9$ & $12 \cdot 8$ \\
B & 22 & 181 & $7 \cdot 7$ & $3 \cdot 3$ & $11 \cdot 0$ \\
C & 30 & 236 & $3 \cdot 8$ & $2 \cdot 9$ & $6 \cdot 7$ \\
D & 26 & 238 & $4 \cdot 6$ & $2 \cdot 5$ & $7 \cdot 1$ \\
\hline
\end{tabular}

A significant excess of hypohaploid over hyperhaploid complements was observed only for Donor A $\left(\chi^{2}=4.57 ; P<0.05\right)$. Differences in the incidences of numerical and structural abnormalities among the various abstinence lengths was not significant, except for Donor $\mathrm{D}\left(\chi^{2}=12 \cdot 36\right.$; $P<0.05)$. Structural aberrations included chromosome breaks, chromosome gaps and acentric fragments.

Statistical analysis of the results demonstrated that there was no significant correlation between sexual abstinence and (1) the overall frequency of chromosomal abnormalities $(P>0 \cdot 10)$ and (2) the incidence of numerical $(0.09<r<0.45 ; \quad P>0.10)$ or structural abnormalities $(0.25<r<0.67 ; P>0.10)$. For each donor, the proportions of $\mathrm{X}$-bearing and $\mathrm{Y}$-bearing spermatozoa were not significantly different from a one-to-one ratio $(P>0.05)$. 


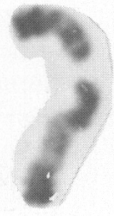

2

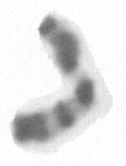

6

10

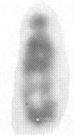

13

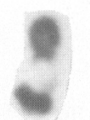

16

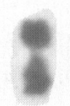

19

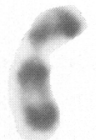

11

14

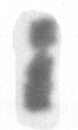

17

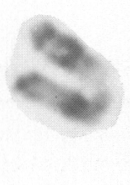

3

4

5

8

9

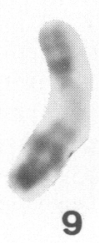

12

X

15

18

Fig. 1. An R-banded karyotype of a normal 23,Y human sperm chromosome complement. 
Table 2. Individual results of sperm chromosomal analysis according to the duration of sexual abstinence

\begin{tabular}{|c|c|c|c|c|c|}
\hline $\begin{array}{l}\text { Length (days) } \\
\text { of sexual } \\
\text { abstinence }\end{array}$ & $\begin{array}{l}\text { No. of sperm } \\
\text { complements } \\
\text { analysed }\end{array}$ & $\begin{array}{c}\text { No. }(\%) \\
\text { hypohaploid* }\end{array}$ & $\begin{array}{c}\text { No. }(\%) \\
\text { hyperhaploid* }\end{array}$ & $\begin{array}{l}\text { No. }(\%) \text { with } \\
\text { structural } \\
\text { abnormalities* }\end{array}$ & $\begin{array}{c}\text { No. }(\%) \text { of } \\
\text { total } \\
\text { abnormalities }\end{array}$ \\
\hline \multicolumn{6}{|l|}{ Donor A } \\
\hline 2 & 75 & $6 \quad(8 \cdot 0)$ & $2(2 \cdot 6)$ & $2(2 \cdot 6)$ & $10(13 \cdot 3)$ \\
\hline 2 & 42 & $4 \quad(9 \cdot 5)$ & - & - & $4(9 \cdot 5)$ \\
\hline 4 & 30 & $3(10-0)$ & - & $1(3 \cdot 3)$ & $4(13 \cdot 3)$ \\
\hline 7 & 39 & $1(2.5)$ & $1(2 \cdot 5)$ & $2(5 \cdot 1)$ & $4(10 \cdot 2)$ \\
\hline 10 & 52 & $2(3 \cdot 8)$ & $1(1 \cdot 9)$ & $4(7 \cdot 6)$ & $7(13 \cdot 4)$ \\
\hline 15 & 41 & $4(9.7)$ & $1(2 \cdot 4)$ & $2(4 \cdot 8)$ & $7(17.0)$ \\
\hline \multicolumn{6}{|l|}{ Donor B } \\
\hline 2 & 39 & $3(7 \cdot 6)$ & - & - & $3 \quad(7 \cdot 6)$ \\
\hline 2 & 42 & $2(4 \cdot 7)$ & $1(2 \cdot 3)$ & $1(2 \cdot 3)$ & $4 \quad(9 \cdot 5)$ \\
\hline 4 & 36 & - & $2(5 \cdot 5)$ & $2(5 \cdot 5)$ & $4(11 \cdot 1)$ \\
\hline 7 & 30 & $2(6 \cdot 6)$ & - & $1(3 \cdot 3)$ & $3(10.0)$ \\
\hline 12 & 34 & $4(11.7)$ & - & $2(5 \cdot 8)$ & $6(17 \cdot 6)$ \\
\hline \multicolumn{6}{|l|}{ Donor C } \\
\hline 2 & 49 & I $(2 \cdot 0)$ & - & $1(2 \cdot 0)$ & $2(4 \cdot 0)$ \\
\hline 2 & 40 & $2(5 \cdot 0)$ & - & - & $2(5.0)$ \\
\hline 4 & 30 & $1 \quad(3 \cdot 3)$ & - & $1(3 \cdot 3)$ & $2(6 \cdot 6)$ \\
\hline 7 & 44 & - & $1(2 \cdot 2)$ & $2(4 \cdot 5)$ & $3(6 \cdot 8)$ \\
\hline 10 & 38 & $3(7.8)$ & - & $1(2 \cdot 6)$ & $4(10.5)$ \\
\hline 15 & 35 & - & $1(2 \cdot 8)$ & $2(5 \cdot 2)$ & $3(8.5)$ \\
\hline \multicolumn{6}{|l|}{ Donor D } \\
\hline 2 & 38 & $2(5 \cdot 2)$ & $2(5 \cdot 2)$ & - & $4(10 \cdot 5)$ \\
\hline 2 & 51 & $1(1.9)$ & - & $1(1.9)$ & $2(3.9)$ \\
\hline 4 & 34 & - & - & - & $\begin{array}{ll}0 & (0.0)\end{array}$ \\
\hline 7 & 42 & $3(7 \cdot 1)$ & $1(2 \cdot 3)$ & - & $4 \quad(9.5)$ \\
\hline 10 & 37 & - & - & $3(8 \cdot 1)$ & $3(8 \cdot 1)$ \\
\hline 15 & 36 & $2(5 \cdot 5)$ & - & $2(5 \cdot 5)$ & $4(11 \cdot 1)$ \\
\hline
\end{tabular}

*Sperm complements with both numerical and structural abnormalities were counted in both categories.

No intra-individual differences in abnormality rates were observed between the two experiments of 2-days' abstinence performed within a 4-month interval $(P>0 \cdot 10)$ (Table 2$)$.

\section{Discussion}

The effects of sexual abstinence have been studied mainly on semen characteristics and divergent results have been reported. Poland et al. (1985) observed a significant increase in semen volume and sperm count according to the abstinence period, while Padova et al. (1988) did not find any significant variation in sperm concentration with delays of abstinence ranging from 2 days to more than 7 days. Sperm ageing was also correlated with a decrease in fertilization rate (Shaver \& Yanagimachi 1978) but, as shown by Smith \& Lodge (1987), the most detrimental fertilization effect results from the association of aged spermatozoa with aged oocytes. In our study, the observed penetration rate was always high (greater than $50 \%$ ). However, because the gamete co-incubation period was varied (from 1 to $3 \mathrm{~h}$ ) to obtain maximal hamster egg penetration, this fertilization rate is not an accurate indication of the effect of sexual abstinence on sperm fertilization capacity.

The overall frequency of chromosomal abnormalities was $9 \cdot 4 \%$, which is similar to the frequencies observed both in our own pool of 957 sperm complements from normal men $(9 \cdot 7 \%)$ and in large studies from different laboratories (Pellestor \& Sèle, 1989). In consideration of these reports, it can be estimated that the frequency of sperm chromosomal abnormalities in normal men is 
approximately $10 \%$. Intra-individual variability was studied on two sperm samples obtained within a 4-month interval. Frequency of abnormalities did not vary significantly in any donor. Brandriff $e t$ al. (1985) also found no significant variability in sperm karyotypes from two donors sampled twice within a 14- and 16-month interval. The incidence of abnormalities in an individual therefore seems to be constant over time. Conversely, inter-individual variability of abnormality rates, reported in all sperm studies, persists with sexual abstinence.

The results of our study do not demonstrate a relationship between the duration of sexual abstinence and the frequency of chromosomal abnormalities in human spermatozoa. These findings disagree with the reports of Martin-Deléon \& Boice $(1982,1985)$ who, in a study of mouse oocytes, observed a significant increase in both the incidence of chromosomal abnormalities and in the severity of these aberrations, according to the abstinence. It must be taken into account that many experimental differences exist between the two studies. In the mouse, Martin-Deléon \& Boice (1982, 1985) used an abstinence period ranging from 2 to 20 days. In the present study, the longest period of abstinence was 15 days but this delay can be considered to be the mean maximal length of abstinence in man. Whereas in the mouse, the incidence of abnormalities increased quickly from 6 days' abstinence (Martin-Deléon \& Boice, 1982), no such tendency was observed in men (Table 1). The cytogenetic analyses of Martin-Deléon \& Boice $(1982,1985)$ were carried out at the first cleavage metaphase of the mouse zygote. Male and female genomes were identified only on the basis of differential condensation of the chromosomes or the presence of a $\mathrm{Y}$ chromosome, but in such a homospecific system, an unequivocal identification of the parental origin of chromosome abnormalities cannot be ensured. This is a problem, all the more so because meiotic chromosomal abnormalities are known to be more common in the female than in the male; the incidence of abnormalities found in mouse oocytes (Santalo et al., 1986), in hamster oocytes (Mikamo \& Kamiguchi, 1983), or in human oocytes (Pellestor \& Sèle, 1988) is always higher than in spermatozoa. When hamster eggs are penetrated by human spermatozoa, human and hamster haploid chromosome sets are obtained, presenting some differences (number, morphology, staining) and the use of a banding technique permits accurate differentiation between human and hamster chromosomes.

Although the number of karyotypes analysed in the present study was high enough to allow a reliable statistical analysis, the criteria for donor selection resulted in both a small number of donors and a narrow age range (22-30 years). Large studies of semen characteristics have shown that spermatogenesis reaches its maximum level in men between the ages of 26 and 35 years (Schwartz et al., 1983), so it would be interesting to investigate the effect of abstinence in a larger age range.

In their conclusion, Martin-Deléon \& Boice (1985) supported the idea of prezygotic selection against chromosomally abnormal spermatozoa, and suggested that in an ageing population unbalanced spermatozoa could gain an advantage either in number or in fertilizing capability. This hypothesis of sperm selection has already been debated and many observations argue against this notion. Ford \& Evans (1973) reported a similar fertilization rate for chromosomally balanced and unbalanced mouse sperm populations. Hamster studies also suggest a lack of selection (Sponta et al., 1984). In sperm studies of human translocation carriers (Pellestor \& Sèle, 1989), the range of abnormalities varies from 19 to $80 \%$, whereas the risk of imbalance at term is only $11 \%$ (Boue \& Gallano, 1984). All these studies demonstrate that chromosomally unbalanced spermatozoa are not at a disadvantage in performing fertilization. It would seem likely that the quality of sperm chromatin is not important and the study of Smith \& Lodge (1987) suggests that aged spermatozoa can fertilize and undergo the initial pronuclear development as well as do unaged spermatozoa, because the pronuclear stage is under control of the eggs.

In fact, such a selection of spermatozoa suggests a close relationship between the sperm genome and both morphology and maturity. Talbot $\&$ Chacon (1981) have pointed out the heterogeneity of a sperm population in reporting that, in vitro, only $10-15 \%$ of cells undergo the acrosome reaction and only capacitated gametes can fuse with oocyte membranes. Due to meiotic segregation, the 
spermatozoa have indeed different genetic contents, but during spermatogenesis all cells are interconnected, so differentiating spermatozoa use genome products of the two parental chromosome sets (Erickson et al., 1981). A relationship between unbalanced haploid genomes and the differentiation of carrier spermatozoa therefore seems unlikely. In addition, Martin \& Rademaker (1988) have demonstrated that there is no correlation between morphology and chromosome abnormalities in human spermatozoa. The most likely effect of ageing is a senescence of spermatozoa. Sperm ageing has been associated with a loss of acrosomal enzymes which could prevent aged spermatozoa from penetrating the zona pellucida (Mann \& Lutwak-Mann, 1975), allowing younger spermatozoa intermixed with old spermatozoa in the corpus epididymidis to have a higher fertilizing capability. This higher fertilizing capability of younger spermatozoa is inconsistent with the notion of an increase in zygote abnormalities due to sperm ageing.

The relationship reported by Milstein-Moscati \& Becak (1981) between the incidence of Down syndrome and long intervals between coitus, independent of the mother's age, could not result from male sexual abstinence alone. Mulcahy \& James (1978) pointed out that though the mean intercourse rate decreased with the duration of marriage when the wife's age was controlled, the incidence of abnormal liveborn did not vary with the duration of marriage. Ageing of spermatozoa and oocytes and delayed fertilization are implicated when there is a low coital rate. Increased abnormal development associated with ageing of ova has been reported for several mammalian species and the rate of spontaneous abortions has been correlated with post-ovulatory ageing of ova (Boue et al., 1975). The major effect of ovum ageing is spindle instability and chromosome dispersion which can lead to a non-disjunction event or the production of a triploid zygote (Szöllösi, 1973). On the other hand, paternal age is a possible contributing factor which may be superimposed upon the effect of sexual abstinence. A paternal age effect in Down syndrome has been reported (Stene et al., 1977) and Tomar et al. (1984) determined that $80 \%$ of de-novo structural rearrangements are of paternal origin. Andrews et al. (1984) observed an increase in abnormal abortuses with increasing paternal age but they did not analyse this independent of maternal age. Thus both the physiological ageing of the gonads and the decline in testosterone with age could contribute to favour abnormal segregation of meiotic chromosomes in man. Nevertheless, in human spermatozoa, Martin \& Rademaker (1987) did not observe a positive relationship between age and the frequency of numerical abnormalities but reported a significant correlation between age and structural abnormalities.

In conclusion, it appears that the incidence of aberration of paternal origin cannot be associated solely with male sexual abstinence. The production of chromosomally abnormal spermatozoa could be an epiphenomenon resulting from the additional effects of paternal and gamete ageing.

This work was supported by a grant from E.D.F. (Comité de Radioprotection), No. BOO.L.25.3L.7657. We thank Dr R. H. Martin and E. Ko, Medical Genetics Clinic, Alberta Children's Hospital, Calgary, Canada, for critical reading of the manuscript.

\section{References}

Andrews, T., Dunlop, W. \& Roberts, D.F. (1984) Cytogenetic studies in spontaneous abortuses. Hum. Genet. 66, 77-84.

Boué, J., Boué, A. \& Lazar, P. (1975) The epidemiology of human spontaneous abortions with chromosomal anomalies. In Aging Gametes, their Biology and Pathology, pp. 330-348. Ed. R. J. Blandau. S. Karger A.G., Basel.

Boué, A. \& Gallano, P. (1984) A collaborative study of the segregation of inherited chromosome structural rearrangements in 1356 prenatal diagnoses. Prenat. Diag. 4, 45-67.
Brandriff, B., Gordon, L., Ashworth, L., Watchmaker, G., Moore, D., Wyrobek, A.J. \& Carrano, A.V. (1985) Chromosomes of human sperm: variability among normal individuals. Hum. Genet. 70, 18-24.

Donahue, R.P. \& Karp, L.E. (1973) Chromosomal anomalies after fertilization of aged, postovulatory mouse oocytes. Am. J. hum. Genet. 25, $24 \mathrm{a}$.

Erickson, R.P., Lewis, S.E. \& Butley, M. (1981) Is haploid gene expression possible for sperm antigens? J. Reprod. Immunol. 3, 195-218.

Ford, C.E. \& Evans, E.P. (1973) Non-expression of genome unbalance in haplophase and early diplo- 
phase of the mouse and incidence of karyotipic abnormality in post-implantation embryos. In Proc. Symp. Institut National de la Santé et de la Recherche Médicale, pp. 271-285. Eds A. Boué \& C. Thibault. INSERM, Paris.

Mann, T. \& Lutwak-Mann, C. (1975) Biochemical aspects of aging in spermatozoa in relation to motility and fertility ability. In Aging Gametes, their Biology and Pathology, pp. 122-134. Ed. R. J. Blandau. S. Karger, A.G., Basel.

Martin, R.H. \& Rademaker, A.W. (1987) The effect of age on the frequency of sperm chromosomal abnormalities in normal men. Am. J. hum. Genet. 41, 484-492.

Martin, R.H. \& Rademaker, A. (1988) The relationship between sperm chromosomal abnormalities and sperm morphology in humans. Mutat. Res. 207, 159-164.

Martin, R.H., Rademaker, A.W., Hildebrand, K., LongSimpson, L., Peterson, D. \& Yamamoto, J. (1987) Variation in the frequency and type of sperm chromosomal abnormalities among normal men. Hum. Genet. 77, 108-114.

Martin-Deléon, P.A. \& Boice, N.L. (1982) Sperm aging in the male and cytogenetic anomalies. An animal model. Hum. Genet. 62, 70-77.

Martin-Deléon, P.A. \& Boice, N.L. (1985) Sperm aging in the male after sexual rest: contribution to chromosome anomalies. Gamete Res. 12, 151-163.

Mikamo, I. \& Kamiguchi, Y. (1983) Primary incidences of spontaneous chromosomal anomalies and their origins and causal mechanisms in the Chinese hamster. Mutat. Res. 108, 265-278.

Milstein-Moscati, I. \& Becak, W. (1981) Occurrence of Down syndrome and human sexual behaviour. Am. J. med. Genet. 9, 211-217.

Mulcahy, M.T.\& James, W. (1978) Down syndrome and parental coital rate. Lancet, 2, 895 .

Nogués, C., Ponsà, M., Vidal, F., Boada, M. \& Egozcue, J. (1988) Effects of aging on the zona pellucida surface of mouse oocytes. J. In Vitro Ferl. Embryo Transfer 5, 225-229.

Padova, G., Tita, P., Briguglia, G. \& Giuffrida, D. (1988) Influence of abstinence length on ejaculate characteristics. Acta eur. fertil. 19, 29-31.

Pellestor, F. \& Sèle, B. (1988) Assessment of aneuploidy in the human female by using cytogenetics of IVF failures. Am. J. hum. Genet. 42, 274-283.
Pellestor, F. \& Sèle, B. (1989) Etude cytogénétique du sperme humain. Méd. Sciences 5, $244-251$.

Poland, M.L., Moghissi, K.S., Giblin, P.T., Ager, J.W. \& Olson, J.N. (1985) Variation of semen measures within normal men. Fert. Steril. 44, 396-398.

Santalo, J., Estop, A.M. \& Egozcue, J. (1986) The chromosome complement of first cleavage mouse embryos after in vitro fertilization. J. In Vitro Fert. Embryo Transfer 3, 99-105.

Schwartz, D., Mayaux, M.J., Spira, A., Moscato, M.L., Jouannet, P., Czyglik, F. \& David, G. (1983) Semen characteristics as a function of age in 833 fertile men. Fert. Steril. 39, 530-535.

Sèle, B., Pellestor, F., Estrade, C., Ostorero, C., Warembourg, E., Gelas, M., Jalbert, H. \& Jalbert, P. (1985) Mise en évidence des chromosomes de spermatozoides humains dans un système hétérospécifique: difficultés techniques. Path. Biol. 9, 875--880.

Shaver, E.L. \& Yanagimachi, R. (1978) The effect of in vitro storage of hamster sperm on fertilization and early development. Gamete Res. 1, 235-242.

Smith, A.L. \& Lodge, J.R. (1987) Interactions of aged gametes: in vitro fertilization using in vitro-aged sperm and in vivo-aged ova in the mouse. Gamete Res. 16, 47.

Sponta, S., Fukui, K. \& Yamamura, H. (1984) Selective elimination of chromosomally unbalanced zygotes at the two cell stage in the Chinese hamster. Cytogenet. Cell Genet. 38, 5-13.

Stene, J., Fisher, G., Stene, E., Mikkelsen, M. \& Petersen, E. (1977) Paternal age effect in Down's syndrome. Ann. Hum. Genet. 40, 299-306.

Szöllösi, D. (1973) The spindle structure in mammalian eggs: the effect of aging. In Proc. Symp. Institut National de la Santé et de la Recherche Médicale, pp. 241-254. Eds A. Boué \& C. Thibault. INSERM, Paris.

Talbot, P. \& Chacon, R.S. (1981) A triple-stain technique for evaluating normal acrosome reactions of human sperm. J. exp. Zool. 215, 201-208.

Tomar, D., Magenis, E., Chamberlin, J., Allen, L., Olson, S., Dowlon, T., Barton, S., Sheehy, R. \& Waggoner, D. (1984) Preferential paternal origin of de novo structural chromosome rearrangements. Am. J. hum. Genet. 34, 115S.

Received 28 February 1990 